\title{
Differences in Ibaraki Virus RNA Segment 3 Sequences from Three Epidemics
}

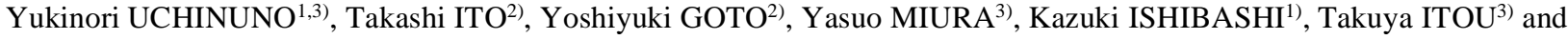 \\ Takeo SAKAI ${ }^{3)}$
}

${ }^{1)}$ Fukuoka Chuo Livestock Hygiene Service Center, 2-1-3 Isouda, Hakata, Fukuoka 816-0081 and ${ }^{2)}$ National Institute of Animal Health, 3-1-5 Kannondai, Tsukuba, Ibaraki 305-0856 and ${ }^{3)}$ Department of Preventive Veterinary Medicine and Animal Health, Nihon University School of Veterinary Medicine, 1866 Kameino, Fujisawa, Kanagawa 252-8510, Japan

(Received 6 December 2002/Accepted 29 July 2003)

\begin{abstract}
Phylogenetic tree and partial nucleotide sequence analysis of RNA segment 3 were conducted to compare the Ibaraki virus (IBAV) strains from three epidemics in Japan, and serotype 2 epizootic hemorrhagic disease virus strains isolated in Australia, Taiwan, and Canada. Each strain was classified relative to the Ibaraki disease (IBAD) epidemics, which occurred in 1959-1960, 1987, or 19971998. In particular, major variation of the gene was identified in the strains isolated after 1997 when a new type of IBAD with the abnormal birth was confirmed. Ibaraki viruses isolated in Japan were more closely related to Taiwanese and Australian strains based on genetics, while the Canadian strain was more distantly related.
\end{abstract}

KEY WORDS: genetic analysis, Ibaraki virus, variant.

J. Vet. Med. Sci. 65(11): 1257-1263, 2003

Ibaraki virus (IBAV) was first isolated from defibrinated blood of affected cattle in Ibaraki Prefecture, Japan in 1959 [18]. IBAV is classified as belonging to the genus Orbivirus in the family Reoviridae and is now known as serotype 2 of epizootic hemorrhagic disease virus (EHDV) [2, 21]. It causes bluetongue-like disease clinical symptoms and pathological findings [17] and has been isolated from naturally infected cattle and sheep [8]. Ibaraki disease (IBAD) caused by IBAV typically manifests the clinical symptoms of a deglutitory disorder in cattle and has broken out in 1950-1952, 1959-1960, 1982, and 1987 in Japan [7, 8, 15, $17,18]$. After ten years, an epidemic of IBAD was observed in 1997-1998 in southwest Japan [15]. However, in the 1997 epidemic of IBAD, cows infected with IBAV frequently had abnormal pregnancies, characterized mainly by abortions and stillbirths. It is extremely likely that these new isolates of the virus were the causal agent of the abnormal pregnancies based on seroepidemical and virological analyses [15].

IBAV has an icosahedral configuration; the virion measures about $55 \mathrm{~nm}$ in diameter, and the capsid consists of 32 capsomeres. One or more virions are enclosed in a pseudoenvelope of the cell membrane origin [9]. EHDV is composed of seven structure proteins (VP1-VP7) and three nonstructural proteins (NS1-NS3) organized in a double-layered capsid containing the 10 double-stranded RNA segments of the viral genome [5, 6, 14]. RNA segment 3 (RNA3) encodes the major inner capsid protein VP3, which contains group-specific antigenic determinants [5, 11]. Researchers demonstrated that reverse transcription-polymerase chain reaction (RT-PCR) with primers based on the sequence of RNA3 was a useful tool for the detection and differentiation of the EHDV serogroup [4, 13, 15].

In this study, we performed comparative sequence analysis of RNA3 genes of IBAV isolated in Japan. A phylogenetic tree was also constructed to investigate the relationship among IBAV strains from three epidemics.

IBAV isolates used in this study from Japan, Taiwan [12], Australia [19], and Canada [1, 2] are listed in Table 1. Seventeen isolates from Japan were classified into three epidemic groups: prototypes isolated during the first recognized epidemic of IBAD in Japan in 1959 (strain No. 2) and 1960 (strain Imaizumi), the 1987 epidemic strains (OA, OI6, FC25-1, FC34-3, Iwagawa, OK75, OKC-13, OCH, OYE, and MS55P), and the 1997-1998 epidemic strains (Hyogo-6, KA84, 97MD70V2, 97MD60, and 98MD57). These isolates were chosen to allow comparison across generations. In addition, the following EHDV serotype 2 (EHDV-2) strains were added for geographic comparisons: CSIRO439 (Australia), Taiwan-41 (Taiwan), and Alberta (Canada).

The viruses were propagated in the HmLu-1 cell line. Total RNA was extracted from infected cells using TRL Zol LS reagent (GIBCO BRL, U.S.A.), according to the manufacturer's instructions. A 660-base pair fragment of RNA3 of IBAV was amplified by RT-PCR by the method of McColl et al. [13]. The primers, IBA1 (5'-CCT AGA TGT TCA ATA GCA AAC CTA ATT-3') and IBA2 (5'-TAA CAT TTC GTT ATA ACA ATA ATA ATT-3'), were developed based on the nucleotide sequence of RNA3 of IBAV. RT-PCR products were cloned and sequenced.

The amplified cDNA fragments were cloned into a pCR 2.1 vector using a TA cloning kit (Invitrogen Corporation, CA, U.S.A.). Competent E. coli cells were transformed, cultured, and plasmid DNA was isolated using the Plasmid Mini Kit (QIAGEN, Cologne, Germany). The cloned DNA was sequenced using an ALFII automated sequencer (Amersham Pharmacia Biotech, Uppsala, Sweden) according to the manufacturer's instructions. The partial RNA3 nucleotide sequences were analyzed by GENETYX Ver. 10 (Software Development, Tokyo, Japan) and a phylogenetic tree was constructed using the CLUSTAL W program in the 


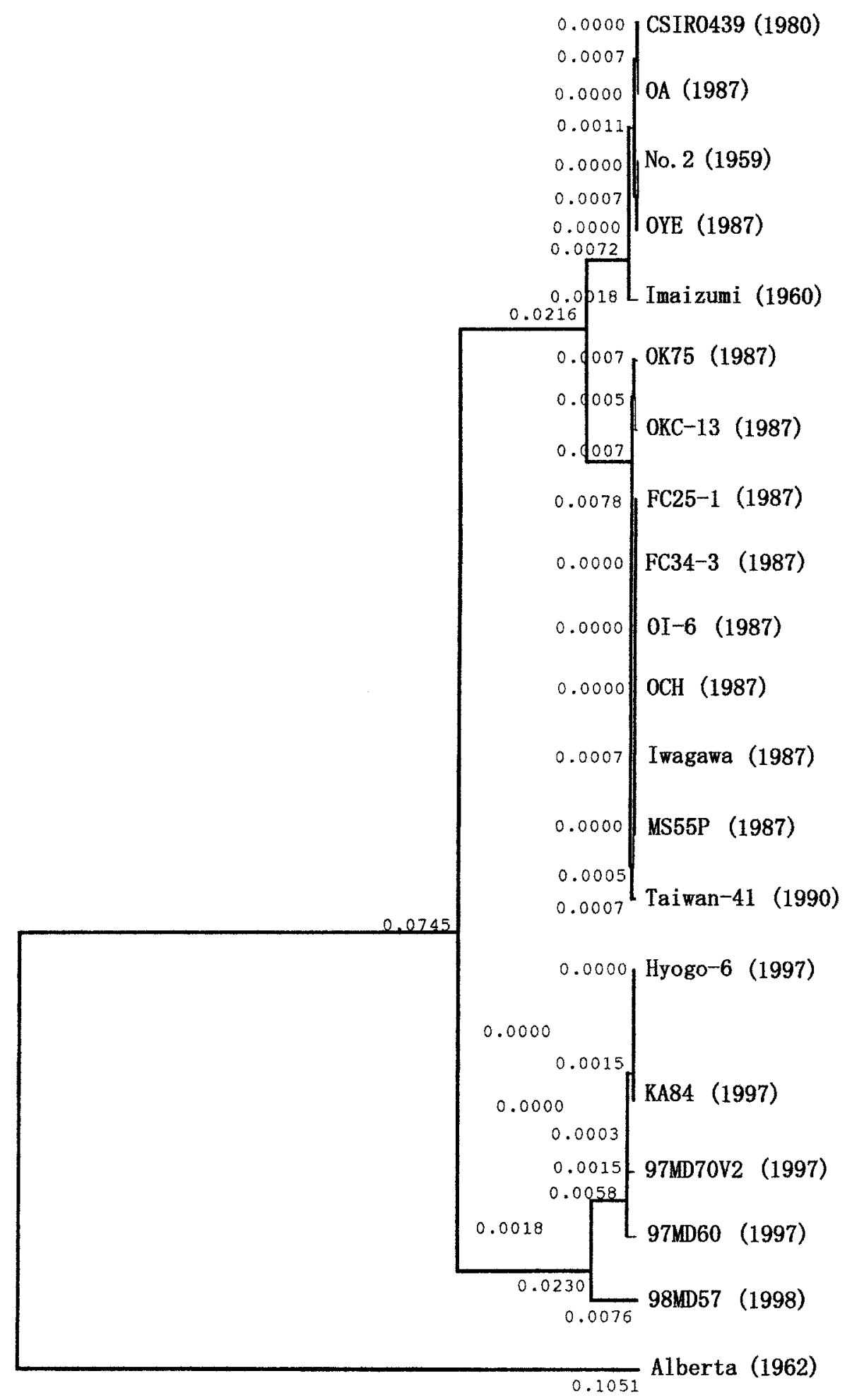

Fig. 1. Phylogenetic tree of RNA segment 3 amplified from cDNA of Ibaraki virus and serotype 2 of epizootic hemorrhagic disease virus strains from Japan, Australia, Taiwan, and Canada. Numbers indicate branch lengths. 

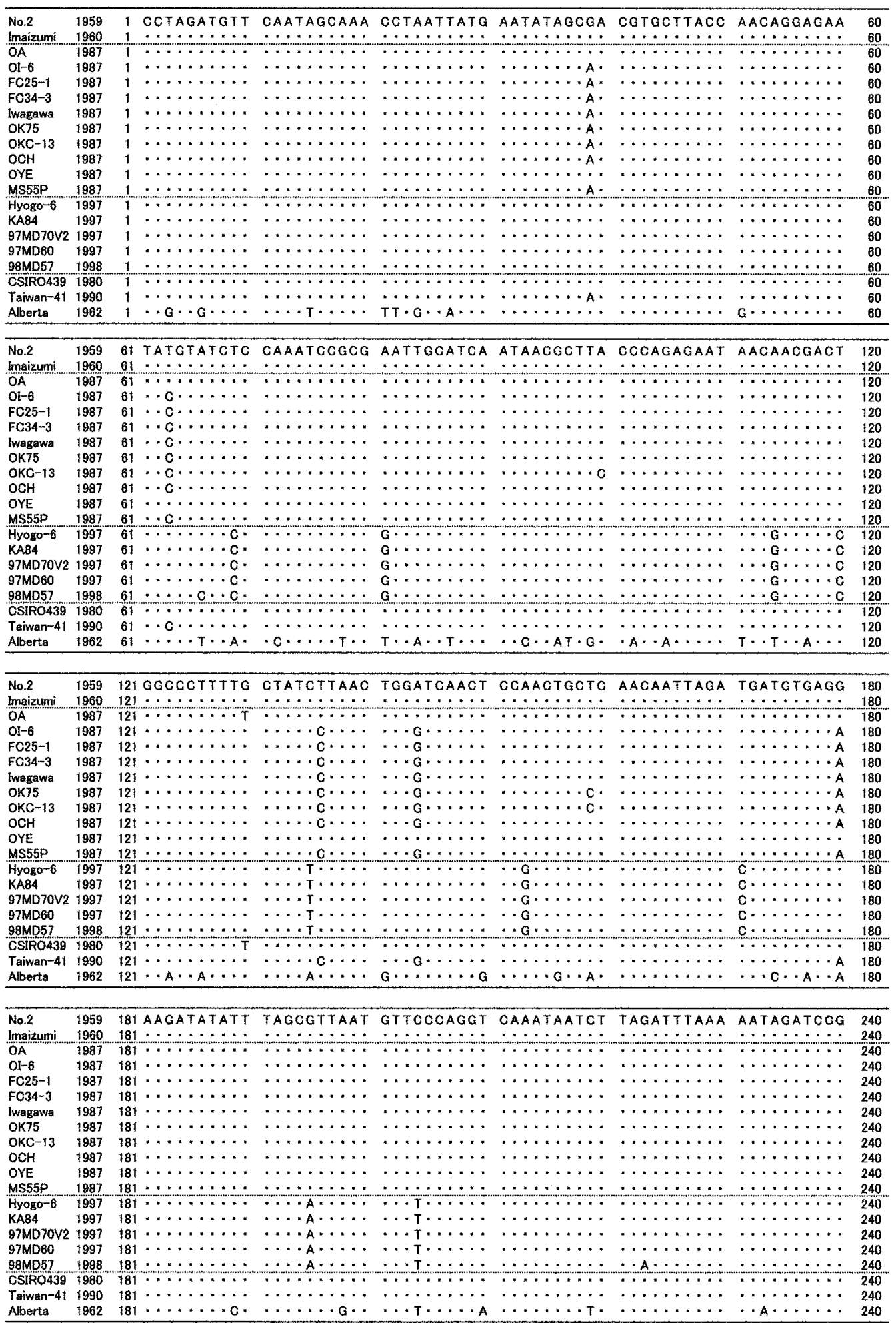

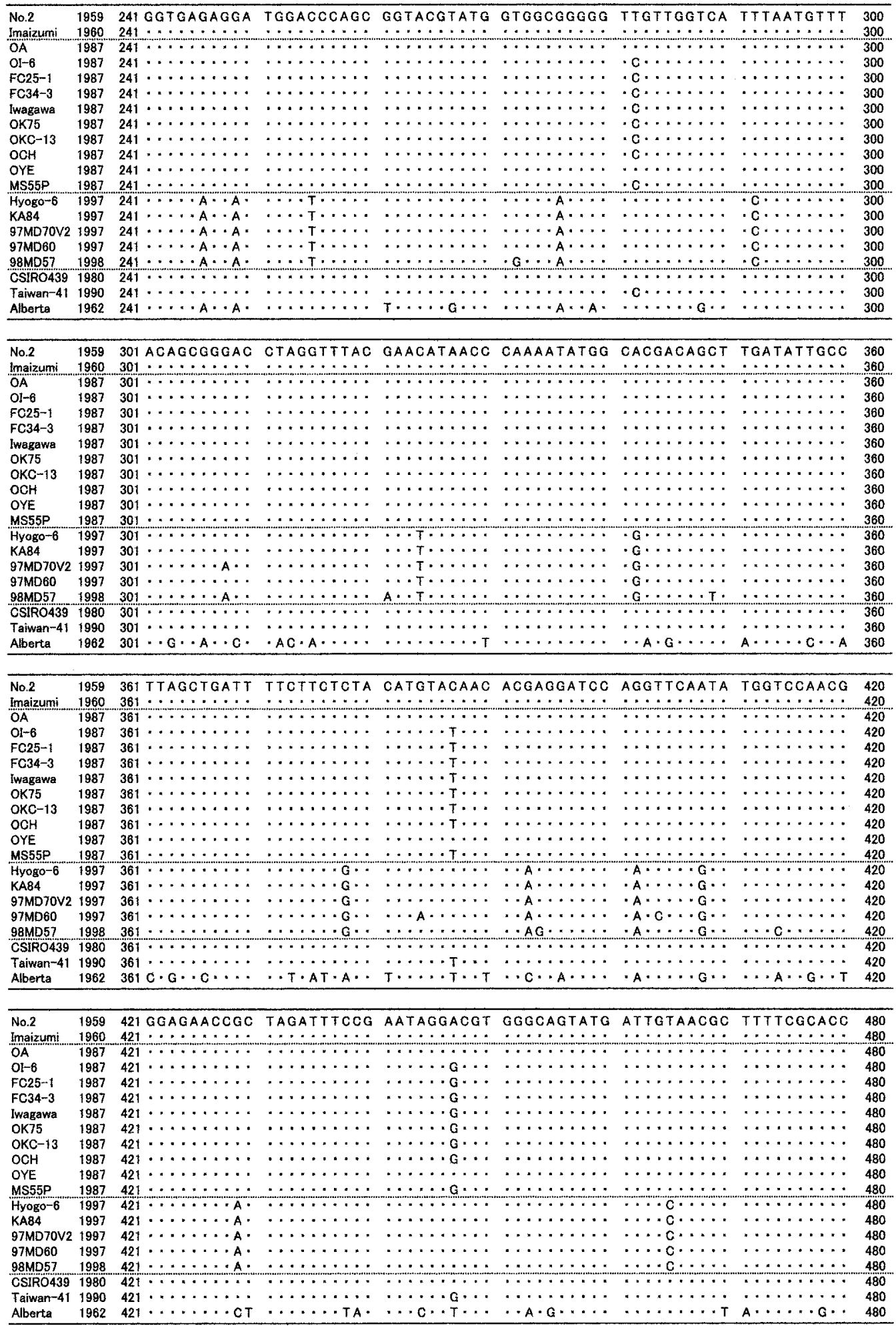

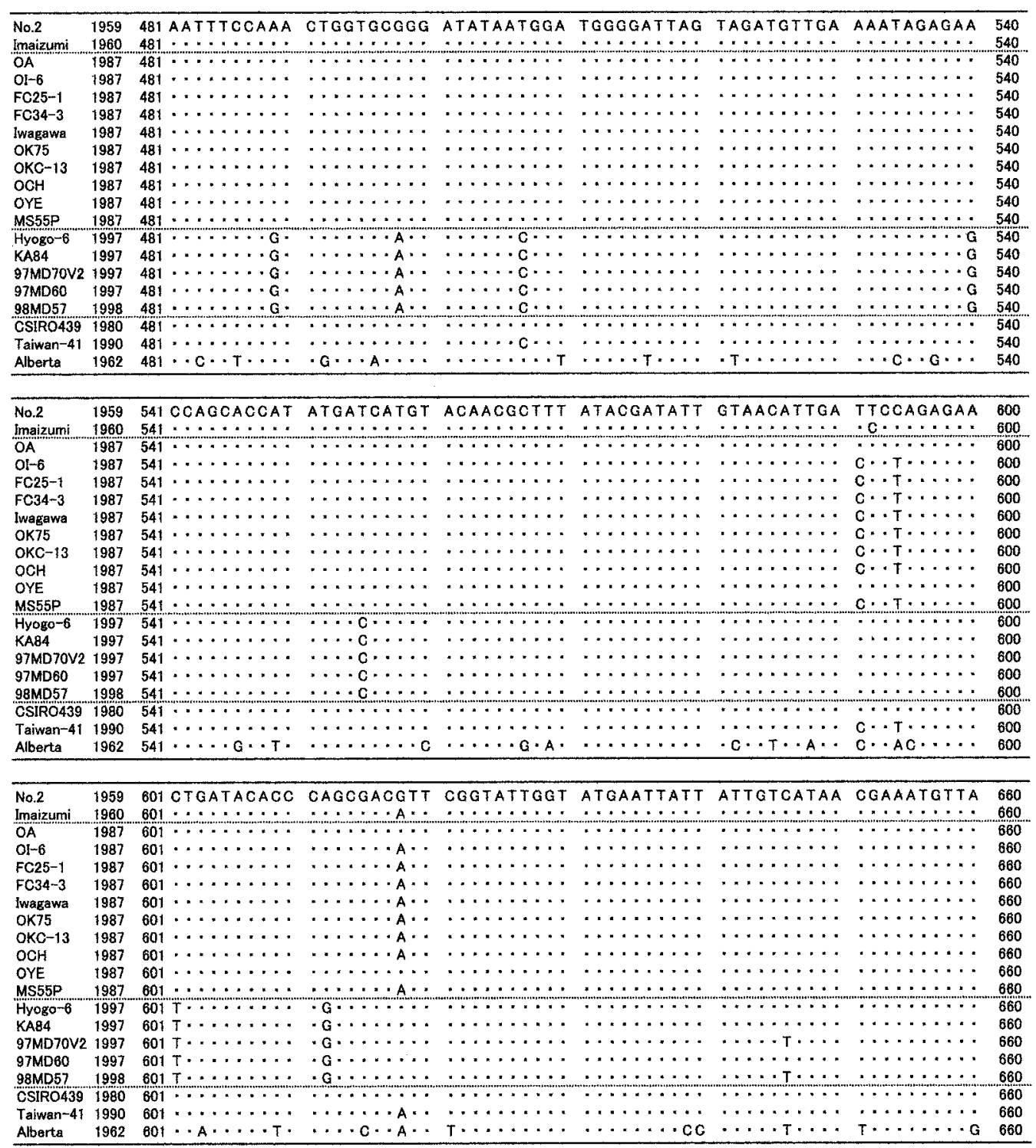

Fig.2. Alignment of the nucleotide sequences of RNA segment 3 of Ibaraki virus and serotype 2 of epizootic hemorrhagic disease virus strains isolated in Japan, Australia, Taiwan, and Canada. Dots indicate identity with IBAV sequence, No. 2.

Info-SINCA system (Fujitsu Kyushu System Engineering, Fukuoka, Japan), employing the unweighted pair-group method using arithmetic mean and neighbor-joining methods [20]. The distances between sequences were estimated using three parameter methods. The reliability of the phylogenetic tree was evaluated by the bootstrap test $(n=500)$.

In a phylogenetic tree, the 20 EHDV-2 strains segregated into five clusters (Fig. 1). The sequences formed two main clusters: one including the Alberta strain isolated in Canada in 1962 and the other consisting of the rest of the isolates. Within the second cluster, the strains were further divided into two groups according the isolation date: 1959-1987 and 1997-1998. Isolates OA and OYE in 1987 and CSIRO439 isolated in Australia in 1980 clustered with the prototype strains. The other major strains of the 1987 isolates clustered with Taiwan-41 isolated in Taiwan in 1990. The 1997 isolates formed one cluster, while the 1998 isolate placed in a separate neighboring cluster. Consequently, greater variation of the gene was observed among the strains isolated after 1997 than among the strains isolated earlier.

The alignment of the RNA3 nucleotide sequences of IBAV and EHDV-2 strains is shown in Fig. 2. With the 
Table 1. Ibaraki virus and serotype 2 of epizootic hemorrhagic disease virus strains used in this experiment

\begin{tabular}{|c|c|c|c|c|}
\hline \multirow{2}{*}{$\begin{array}{l}\text { Isolates } \\
\text { No. } 2\end{array}$} & \multicolumn{2}{|c|}{$\begin{array}{l}\text { Year and Place of } \\
\text { isolation }\end{array}$} & \multirow{2}{*}{$\begin{array}{c}\text { Source } \\
\text { affected cattle blood }\end{array}$} & \multirow{2}{*}{$\begin{array}{c}\begin{array}{c}\text { DDBJ } \\
\text { Accession No. }\end{array} \\
\text { AB106900 }\end{array}$} \\
\hline & 1959 & Ibaraki & & \\
\hline Imaizumi & 1960 & Aichi & affected cattle blood & AB106901 \\
\hline $\mathrm{OA}^{-}$ & 1987 & Oita & affected cattle blood & $\mathrm{AB} 106902$ \\
\hline OI-6 & 1987 & Oita & affected cattle blood & AB106903 \\
\hline FC25-1 & 1987 & Kagoshima & Culicoides species & AB106904 \\
\hline FC34-3 & 1987 & Kagoshima & Culicoides species & AB106905 \\
\hline Iwagawa & 1987 & Kagoshima & Culicoides maculatus & AB106906 \\
\hline OK75 & 1987 & Okinawa & affected cattle blood & AB106907 \\
\hline OKC-13 & 1987 & Okinawa & Culicoides species & AB106908 \\
\hline $\mathrm{OCH}$ & 1987 & Okinawa & Culicoides species & AB106909 \\
\hline OYE & 1987 & Okinawa & affected cattle blood & AB107802 \\
\hline MS55P & 1987 & Miyazaki & affected cattle blood & AB107801 \\
\hline Hyogo-6 & 1997 & Hyogo & affected cattle blood & $\mathrm{AB} 107800$ \\
\hline KA84 & 1997 & Kagoshima & RNA from blood ${ }^{a}$ & AB107799 \\
\hline 97MD70V2 & 1997 & Fukuoka & abortus fetus brain & AB107798 \\
\hline 97MD60 & 1997 & Fukuoka & affected cattle blood & AB107797 \\
\hline 98MD57 & 1998 & Fukuoka & affected cattle blood & AB 107803 \\
\hline CSIRO439 & 1980 & Australia & affected cattle blood & $\overline{\mathrm{AB}} \overline{107 \overline{7}} \overline{\mathrm{C}}$ \\
\hline Taiwan-41 & 1990 & Taiwan & affected cattle blood & AB107795 \\
\hline Alberta & 1962 & Canada & affected deer blood & AB107794 \\
\hline
\end{tabular}

a) Viral RNA was obtained by RT-PCR from the blood of cattle, but the virus was not directly isolated.

Table 2. Pairwise comparisons of nucleotide sequence homology of RNA segmet 3 Ibaraki virus and serotype 2 of epizootic hemorrhagic disease virus strains

\begin{tabular}{|c|c|c|c|c|c|c|c|c|c|c|c|c|c|c|c|c|c|c|c|c|c|}
\hline \multirow{2}{*}{$\frac{\text { Isolate }}{\text { No. } 2}$} & \multirow[b]{2}{*}{1959} & \multirow{2}{*}{$\begin{array}{c}\text { No. } 2 \\
-\end{array}$} & \multirow{2}{*}{ Imaizumi } & \multirow[t]{2}{*}{$\mathrm{OA}$} & \multirow[t]{2}{*}{ OI-6 } & \multirow[t]{2}{*}{ FC25-1 } & FC34-3 & \multirow[t]{2}{*}{ Iwagawa } & \multirow[t]{2}{*}{ OK75 } & \multirow[t]{2}{*}{ OKC-13 } & \multirow[t]{2}{*}{$\mathrm{OCH}$} & \multirow[t]{2}{*}{ OYE } & \multirow[t]{2}{*}{ MS55P } & \multirow[t]{2}{*}{ Hyogo-6 } & \multicolumn{3}{|c|}{ KA84 97MD70V2 97MD60 } & \multicolumn{4}{|c|}{ 98MD57 CSIR0439 Taiwan-41 Alberta } \\
\hline & & & & & & & & & & & & & & & & & & & & & \\
\hline Imaizumi & 1960 & 99.7 & - & & & & & & & & & & & & & & & & & & \\
\hline $\mathrm{OA}$ & 1987 & 99.8 & 99.5 & - & & & & & & & & & & & & & & & & & \\
\hline OI-6 & 1987 & 98.3 & 98.3 & 98.2 & - & & & & & & & & & & & & & & & & \\
\hline FC25-1 & 1987 & 98.3 & 98.3 & 98.2 & 100 & - & & & & & & & & & & & & & & & \\
\hline FC34-3 & 1987 & 98.3 & 98.3 & 98.2 & 100 & 100 & - & & & & & & & & & & & & & & \\
\hline Iwagawa & 1987 & 98.3 & 98.3 & 98.2 & 100 & 100 & 100 & - & & & & & & & & & & & & & \\
\hline OK75 & 1987 & 98.2 & 98.2 & 98.0 & 99.8 & 99.8 & 99.8 & 99.8 & - & & & & & & & & & & & & \\
\hline OKC-13 & 1987 & 98.0 & 98.0 & 97.9 & 99.7 & 99.7 & 99.7 & 99.7 & 99.8 & - & & & & & & & & & & & \\
\hline $\mathrm{OCH}$ & 1987 & 98.3 & 98.3 & 98.2 & 100 & 100 & 100 & 100 & 99.8 & 99.7 & - & & & & & & & & & & \\
\hline OYE & 1987 & 100 & 99.7 & 99.8 & 98.3 & 98.3 & 98.3 & 98.3 & 98.2 & 98.0 & 98.3 & - & & & & & & & & & \\
\hline MS55P & 1987 & 98.3 & 98.3 & 98.2 & 100 & 100 & 100 & 100 & 99.8 & 99.7 & 100 & 98.3 & - & & & & & & & & \\
\hline Hyogo-6 & 1997 & 95.6 & 95.3 & 95.5 & 93.9 & 93.9 & 93.9 & 93.9 & 93.8 & 93.6 & 93.9 & 95.6 & 93.9 & - & & & & & & & \\
\hline KA84 & 1997 & 95.6 & 95.3 & 95.5 & 93.9 & 93.9 & 93.9 & 93.9 & 93.8 & 93.6 & 93.9 & 95.6 & 93.9 & 100 & - & & & & & & \\
\hline 97MD70V2 & 1997 & 95.3 & 95.0 & 95.2 & 93.6 & 93.6 & 93.6 & 93.6 & 93.5 & 93.3 & 93.6 & 95.3 & 93.6 & 99.7 & 99.7 & - & & & & & \\
\hline 97MD60 & 1997 & 95.3 & 95.0 & 95.2 & 93.6 & 93.6 & 93.6 & 93.6 & 93.5 & 93.3 & 93.6 & 95.3 & 93.6 & 99.7 & 99.7 & 99.4 & - & & & & \\
\hline 98MD57 & 1998 & 94.1 & 93.8 & 93.9 & 92.4 & 92.4 & 92.4 & 92.4 & 92.3 & 92.1 & 92.4 & 94.1 & 92.4 & 98.5 & 98.5 & 98.8 & 98.2 & - & & & \\
\hline CSIRO439 & 1980 & 99.8 & 99.5 & 100 & 98.2 & 98.2 & 98.2 & 98.2 & 98.0 & 97.9 & 98.2 & 99.8 & 98.2 & 95.5 & 95.5 & $95 . \overline{2}$ & 95.2 & 93.9 & - & & \\
\hline Taiwan-41 & 1990 & 98.2 & 98.2 & 98.0 & 99.8 & 99.8 & 99.8 & 99.8 & 99.7 & 99.5 & 99.8 & 98.2 & 99.8 & 94.1 & 94.1 & 93.8 & 93.8 & 92.6 & 98.0 & - & \\
\hline Alberta & 1962 & 82.4 & 82.4 & 82.2 & 82.2 & 82.2 & 82.2 & 82.2 & 82.2 & 82.1 & 82.2 & 82.4 & 82.2 & 80.9 & 80.9 & 80.9 & 80.6 & 80.0 & 82.2 & 82.1 & - \\
\hline
\end{tabular}

exception of isolates OA and OYE, the sequences obtained from the isolates in the 1987 epidemic differed from strain No. 2 at 11 positions: 49, 63, 136, 144, 180, 282, 387, 447, 591, 594, and 618. Strains OA and OYE were isolated from cows infected with IBAD. Neither of the affected cows had been inoculated with the IBAD vaccine, so these strains were not of the same origin as the vaccine. Therefore, it is possible to conclude that the isolates of the 1987 epidemic consist of two varieties of IBAV strains closely related to the prototype and strains with gene structures differing from the prototype. There are 29 nucleotide substitutions similarly in the isolates in 1997 and 1998 as compared with strain No. 2. However, they were not found in the isolates in 1987, and the 11 nucleotide changes that observed simi- 
larly in the 1987 isolates were not detected in the 1997-1998 isolates.

Pairwise nucleotide sequence homology analyses of RNA3 of the IBAV and EHDV-2 strains are shown in Table 2. Strains OA and OYE showed very high identities of $99.8 \%$ and $100 \%$, respectively, with strain No. 2, while other 1987 isolates had identities varying from 98.0 to $98.3 \%$. The 1997-1998 isolates showed lower identity with strain No. 2; nucleotide homologies varied from 94.1 (98MD57) to $95.6 \%$ (Hyogo-6 and KA84). Sequences homologies within the group of 1987 isolates were 97.9 to $100 \%$, and 98.2 to $100 \%$ for the group of 1997-1998 isolates, suggesting that the strains are closely related within each group.

Sequence homology between the 1987 and 1997-1998 isolate groups ranged from 92.1 to $95.6 \%$ showing lower identities than between 1987 group and strain No. 2. Isolate 97MD60 from the blood of IBAD affected cattle and isolate 97MD70V2 from the brain of an aborted fetus, isolated in the same year and place, showed a high identity of $99.4 \%$. This suggests that the 1997 isolates had the same origin, but spread widely causing abnormal births in addition to the previously observed manifestations of the disease. In addition, the nucleotide sequence homology also recognized the 1998 isolates as being slightly different from the 1997 isolates, with the alignment of RNA3 showing that the 1997 isolates and 1998 isolates consistently varied at 29 positions. Consequently, it was suggested that the 1998 isolate is a variant of the 1997 isolates.

Three EHD-2 strains isolated outside of Japan were also analyzed. CSIRO439 isolated in Australia showed high identities with prototype strains (99.5 to $99.8 \%$ ) and the 1987 isolates ( 97.9 to $100 \%$ ), but lower identities with the 1997-1998 isolates (93.9 to 95.5\%). Taiwan-41 showed high identity with prototype strains $(98.2 \%), 1987$ isolates (98.0 to $99.8 \%$ ), and CSIRO439 (98.0\%). Isolate Alberta from Canada showed low identities with the prototype strains $(82.4 \%), 1987$ isolates (82.1 to $82.4 \%), 1997-1998$ isolates (80.0 to $80.9 \%)$, CSIRO439 (82.2\%), and Taiwan$41(82.1 \%)$.

It was demonstrated that IBAV isolated in Japan genetically changed each year. In particular, large variation of the gene was recognized in the strains isolated in 1997-1998 when the new type of IBAD with the abnormal birth was confirmed. EHD-2 viruses isolated in Japan were recog- nized to be genetically close to Asian and Australian strains, while the North America strain was distantly related, as described previously $[3,10,16]$. More sequence data of isolates from many countries are needed to further elucidate the origin of the IBAV isolated in 1997.

\section{REFERENCES}

1. Campbell, C. H., Barber, T. L. and Jochim, M. M. 1978. Vet. Microbiol. 3: 15-22.

2. Campbell, C. H. and St. George, T. D. 1986. Aust. Vet. J. 63: 233.

3. Cheney, I. W., Larson, M. D., Mecham, J. O. and Wilson, W. C. 1995. Virus Res. 36: 279-286.

4. Harding, M. J., Prud'homme, I., Rola, J. and Dulac, G. C. 1996. Can J. Vet. Res. 60: 59-64.

5. Huismans, H., Bremer, C. W. and Barber, T. L. 1979. Onderstepoort J. Vet. Res. 46: 95-104.

6. Huismans, H. and Erasmus, B. J. 1981. Onderstepoort J. Vet. Res. 48: $51-58$.

7. Inaba, Y., Tanaka, Y., Ishii, S., Morimoto, T. and Sato, K. 1970. Jpn. J. Microbiol. 14: 351-360.

8. Inaba, Y. 1975. Aust. Vet. J. 51: 178-185.

9. Ito, Y., Tanaka, Y., Inaba, Y. and Omori, T. 1973. Arch. Gesamte Virusforsch. 40: 29-46.

10. Iwata, H., Manabe, S., Yoshida, A., Pereira, E. M. and Inoue, T. 2001. J. Vet. Med. Sci. 63: 73-78.

11. Le Blois, H., Fayard, B., Urakawa, T. and Roy, P. 1991. J. Virol. 65: 4821-4831.

12. Liao, Y. K., Lu, Y. S., Huang, S. T. and Lee, S. H. 1996. J. Chin. Soc. Vet. Sci. 22: 183-191.

13. McColl, K. A. and Gould, A. R. 1991. Virus Res. 21: 19-34.

14. Mecham, J. O. and Dean, V. C. 1988. J. Gen. Virol. 69: 12551262.

15. Ohashi, S., Yoshida, K., Watanabe, Y. and Tsuda, T. 1999. J. Clin. Microbiol. 37: 3800-3803.

16. Ohashi, S., Yoshida, K., Yanase, T. and Tsuda, T. 2002. J. Clin. Microbiol. 40: 3684-3688.

17. Omori, T., Inaba, Y., Morimoto, T., Tanaka, Y., Ishitani, R., Kurogi, H., Munakata, K., Matsuda, K. and Matumoto, M. 1969. Jpn. J. Microbiol. 13: 139-157.

18. Omori, T., Inaba, Y., Morimoto, T., Tanaka, Y., Kono, M., Kurogi, H. and Matsumoto, M. 1969. Jpn. J. Microbiol. 13: 159-168.

19. Parsonson, I. M. and Snowdon, W. A. 1985. Prog. Clin. Biol. Res. 178: $27-35$.

20. Saitou, N. and Nei, N. 1987. Mol. Biol. Evol. 44: 406-425.

21. Sugiyama, M., Hirayama, N., Sasaki, H., Sugimura, T., Minamoto, N. and Kinjo, T. 1989. Res. Vet. Sci. 46: 283-285. 